\title{
CSAs: the consumer-farmer connection
}

\author{
Gail Feenstra
}

Since the first two community supported agriculture groups (CSAs) were formed in Massachusetts and New Hampshire in 1985, subscription farming has attracted increasing attention around the country. CSAs are partnerships between farmers and consumers in which both parties share the benefits and risks of farming. Consumers make a commitment to a particular farmer by paying ahead of time (on a yearly, quarterly or monthly basis) for weekly deliveries of fresh, seasonal, often organic vegetables, fruits and other farm products. Farmers use these advance payments as sources of working capital.

CSAs vary widely with full-share prices ranging from about $\$ 200$ to $\$ 700$ per year. Full Belly Farm, one of several CSA programs in the Capay Valley, organically grows 40 acres of nuts and 40 to 70 acres of row crops year-round.

Full Belly's CSA illustrates the flexibility of the model. The CSA was added to an already diverse marketing structure, which included wholesale and retail outlets and farmers' markets. Subscribers are allowed to pay as little as 1 month in advance. Full Belly charges $\$ 10$ per week for a box. A typical box in November might include 1 pound of walnuts, 1 bunch of turnips, 1 bunch

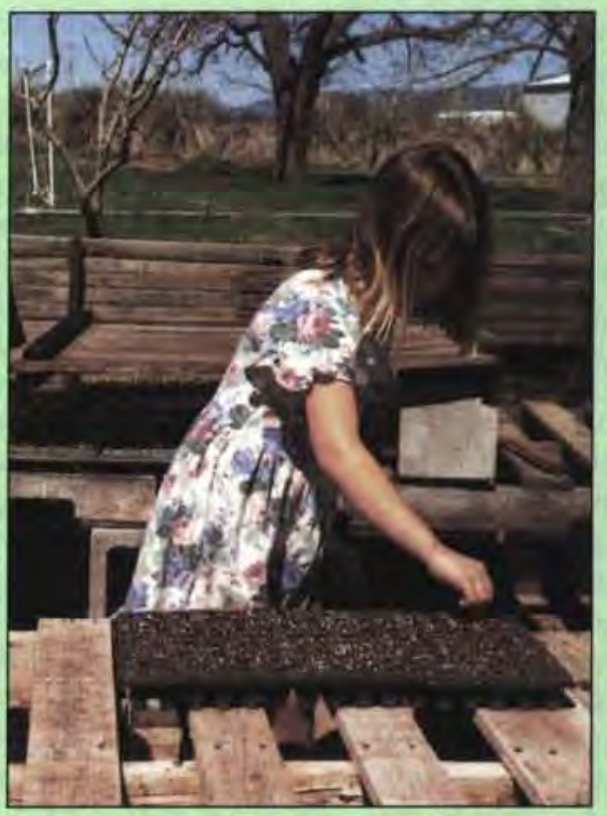

CSA members are invited to the farm for work days. Davis resident Heather Feenstra, 8, plants seeds.
Biodynamic Farming and Gardening Association, and probably twice that many operate across the country, notes Andrew Lorand, CSA consultant. The Association lists 25 active CSAs in California; however, this figure may be an underestimate as some are unrecorded. A CSA conference held in December 1993 at UC Davis drew more than 120 participants, most of whom were small, family farmers in Northern California. Many participants operated unrecorded CSAs or were interested in starting one. A similar conference in Southern California in March 1994 attracted almost 70 participants. Both conferences focused on practical, "how-to" information and included farm tours.

Today, most people never see the sources of their food, and are passive recipients in a global food production and distribution system. In CSAs, farmers teach consumers about agriculture. Participants in CSAs become part of the cycle of production and consumption by learning how to eat seasonally, by providing economic support for farm families and by experiencing the life and work on a farm.

Over the last 15 years, CSAs have supported local economic development efforts, particularly in the eastern United States. For example, some are using the regular CSA to finance of beets, 2 heads of lettuce, 1 bunch of green onions, 1 butternut squash, 2 pounds of potatoes, 1 bunch of red kale and 1 napa cabbage.

Full Belly delivers to the Bay Area and the Palo Alto area (as of December 1993). Newsletters accompanying the delivery tell subscribers what is going on at the farm - eagle sightings, pest problems, new plantings, etc. as well as list the items in the box and how to store and use them. In addition, subscribers are invited to the farm each year for farm work days. These "hands-on" experiences on the farm, in addition to the newsletters and the year-long supply of seasonal vegetables, provide consumers with a much deeper understanding of agriculture and a commitment to the farmers that grow their food.

CSAs have existed in Japan and Europe since the mid1960s. Although CSAs were not established in the United States until 1985, today, about 450 CSAs are listed by the other components of their programs in which food is grown for soup kitchens and food banks, or grown by homeless people in the community. Other CSAs are making connections with institutional kitchens, school food service programs, summer feeding programs, elderly feeding programs or commissaries run by large companies in the community. These community development strategies are all intriguing possibilities for California CSAs as they continue to mature.

G. Feenstra is Food Systems Analyst, Sustainable Agriculture Research and Education Program, UC Davis. Proceedings from the 1993 UC Davis CSA conference are available for $\$ 8$ through the Small Farm Center. For more information or for listings of CSAs, contact the Biodynamic Farming and Gardening Association (800) 516-7797. 